\title{
Impaired activation of murine platelets lacking $\mathbf{G} \alpha_{\mathbf{i} 2}$
}

\author{
Hans-Michael Jantzen, ${ }^{1}$ David S. Milstone, ${ }^{2}$ Laurent Gousset, ${ }^{1}$ Pamela B. Conley, ${ }^{1}$ \\ and Richard M. Mortensen ${ }^{3}$ \\ ${ }^{1}$ COR Therapeutics Inc., South San Francisco, California, USA \\ ${ }^{2}$ Department of Pathology, Brigham and Women's Hospital and Harvard Medical School, Boston, Massachusetts, USA \\ ${ }^{3}$ Department of Physiology and Medicine (Endocrine), University of Michigan Medical School, Ann Arbor, Michigan, USA \\ Address correspondence to: Pamela B. Conley, COR Therapeutics Inc., 256 East Grand Avenue, South San Francisco, \\ California 94080, USA. Phone: (650) 244-6839; Fax: (650) 244-9270; E-mail: pconley@corr.com. \\ Or to: Hans-Michael Jantzen. Phone: (415) 431-2088; Fax: (650) 244-9270; E-mail: hmjantzen@worldnet.att.net.
}

Received for publication March 27, 2001, and accepted in revised form June 18, 2001.

The intracellular signaling pathways by which $G$ protein-coupled receptors on the platelet surface initiate aggregation, a critical process for hemostasis and thrombosis, are not well understood. In particular, the contribution of the $\mathrm{G}_{i}$ pathway has not been directly addressed. We have investigated the activation of platelets from mice in which the gene for the predominant platelet $G \alpha_{i}$ subtype, $G \alpha_{i 2}$, has been disrupted. In intact platelets from $\mathrm{G \alpha}_{\mathrm{i} 2}$-deficient mice, the inhibition of adenylyl cyclase by ADP was found to be partially impaired compared with wild-type platelets. Moreover, both ADPdependent platelet aggregation and the activation of the integrin $\alpha I I b \beta 3$ (GPIIb-IIIa) were strongly reduced in platelets from $\mathrm{G} \alpha_{\mathrm{i} 2}$-deficient mice. In addition, $\mathrm{G} \alpha_{\mathrm{i} 2}$-deficient platelets displayed impaired activation at low thrombin concentrations. This defect was mimicked by blocking the adenylyl cyclase-coupled platelet $\mathrm{ADP}$ receptor $\left(\mathrm{P}_{2} \mathrm{Y}_{12}\right)$ on wild-type platelets with a selective antagonist. These observations suggest that $\mathrm{G \alpha}_{\mathrm{i} 2}$ is involved in the inhibition of platelet adenylyl cyclase in vivo and is a critical component of the signaling pathway for integrin activation by ADP, resulting in platelet aggregation. In addition, thrombin-dependent activation of mouse platelets is mediated, at least in part, by secreted ADP acting on the $\mathrm{G}_{\mathrm{i} 2}$-linked ADP receptor.

J. Clin. Invest. 108:477-483 (2001). DOI:10.1172/JCI200112818.

\section{Introduction}

Platelets play a critical role in hemostasis and thrombosis, and drugs inhibiting platelet aggregation are effective antithrombotics. Platelet aggregation requires induction of an active conformation of the integrin $\alpha \operatorname{IIb} \beta 3$ (GPIIb-IIIa), capable of binding soluble fibrinogen and thus cross-linking the platelets. The signaling pathways leading to integrin activation (inside-out signaling) are not well understood (1). Most platelet agonists (e.g., thrombin, ADP, thromboxane $\mathrm{A}_{2}$, epinephrine, and serotonin) bind to $G$ protein-coupled receptors on the platelet surface. This results in the activation of heterotrimeric $\mathrm{G}$ proteins consisting of various $\alpha$ and $\beta \gamma$ subunits that initiate multiple signaling pathways by interacting with downstream effectors. Platelets express $\mathrm{G} \alpha_{\mathrm{s}}, \mathrm{G} \alpha_{\mathrm{q}}, \mathrm{G \alpha}_{12 / 13}, \mathrm{G} \alpha_{\mathrm{z}}, \mathrm{G \alpha}_{\mathrm{i} 2}$, and $\mathrm{G} \alpha_{\mathrm{i} 3}(2-5)$. Whereas $\mathrm{G} \alpha_{s}$ appears to mediate prostacyclin-dependent platelet inhibition by stimulating adenylyl cyclase, $\mathrm{G} \alpha_{\mathrm{q}}$ is known to activate phospholipase $\mathrm{C}$, resulting in release of intracellular calcium and activation of protein kinase C. $\mathrm{G \alpha}_{12 / 13}$ might be involved in events leading to platelet shape change, and $\mathrm{G} \alpha_{z}$ is capable of inhibition of adenylyl cyclase. Similarly, it has been shown in other cells that $\mathrm{G} \alpha_{\mathrm{i} 2}$ and $\mathrm{G} \alpha_{\mathrm{i} 3}$ can mediate repression of cAMP formation whereas the released $\beta \gamma$ subunits may activate phospholipase $C \beta$ or other signaling molecules $(4,5)$. The requirement of intracellular calcium mobilization and the $G_{q}$ pathway for platelet aggregation has been well established. Platelets from mice in which the gene for $\mathrm{G} \alpha_{\mathrm{q}}$ has been disrupted are defective in calcium mobilization and aggregation by all agonists (6). Of the inhibitory $\mathrm{G}$ proteins in platelets, only $\mathrm{G} \alpha_{z}$ has been investigated in vivo. Platelets from $\mathrm{G \alpha}_{\mathrm{z}}$-knockout mice appear abnormal only for epinephrine-mediated inhibition of adenylyl cyclase and the potentiating effect of epinephrine on aggregation induced by other agonists (7).

Recently, however, the potential relevance of the $G_{i}$ pathway for platelet activation has been implied from pharmacological studies. For example, ADP-dependent aggregation requires not only activation of a receptor mediating calcium mobilization $\left(\mathrm{P}_{2} \mathrm{Y}_{1}\right)$, but also concomitant stimulation of an ADP receptor coupled to the inhibition of adenylyl cyclase $\left(\mathrm{P}_{2} \mathrm{Y}_{12}\right.$, previously called $\mathrm{P} 2 \mathrm{~T}_{\mathrm{AC}}, \mathrm{P} \mathrm{Y}_{\mathrm{ADP}}, \mathrm{P} 2 \mathrm{Y}_{\mathrm{AC}}, \mathrm{P} 2 \mathrm{Y}_{\mathrm{cyc}}$ ) (8-14). Furthermore, after blockade of the $\mathrm{P}_{2} \mathrm{Y}_{12}$ receptor, ADPdependent aggregation could be rescued by epinephrine, which lowers cAMP levels $(10,15)$. Therefore, in addition to the $G_{q}$ pathway, it appears that full platelet aggregation requires activation of receptors that are capable of inhibiting adenylyl cyclase and are likely to couple to a $G$ protein of the $G_{i}$ family. Indeed, in isolated human platelet membranes, stimulation of ADP receptors or the PAR1 thrombin receptor resulted in activation of $\mathrm{G \alpha}_{\mathrm{i} 2}$ (3). However, this does not mean that adenylyl cyclase inhibition or $\mathrm{G}_{i}$ protein is part of the signaling cascade leading to integrin activation and 
platelet aggregation. In fact, lowering cAMP levels using an adenylyl cyclase inhibitor did not induce platelet aggregation, even with concomitant activation of the $\mathrm{G}_{\mathrm{q}}$ pathway (16-18). Thus, it was assumed previously that repression of the cAMP pathway does not lead to aggregation, although low cAMP levels are required to permit aggregation.

It remains to be clarified which of the inhibitory $G$ proteins $\left(G_{i 2}, G_{i 3}, G_{z}\right)$ mediate inhibition of adenylyl cyclase in intact platelets, and more importantly, whether a $G_{i}$ protein is involved in the pathway leading to integrin activation and aggregation. In the present study we have investigated the role of the predominant platelet $G \alpha_{i}$ protein, $\mathrm{G \alpha}_{\mathrm{i} 2}$, in thrombin, epinephrine, and ADPdependent platelet activation by using platelets from mice in which the gene for the $\alpha$ subunit $\mathrm{G \alpha}_{\mathrm{i} 2}$ has been disrupted. $G \alpha_{i 2}{ }^{-/-}$mouse strains have been established, but their platelet function has not been reported $(19,20)$. Because released ADP appears to be a crucial cofactor of other platelet agonists as well (21), we have used the selective ADP receptor antagonist 2-methylthioadenosine 5 '-monophosphate (2MeSAMP) to determine the contribution of released ADP activating a $\mathrm{G} \alpha_{\mathrm{i} 2}$-coupled $\mathrm{ADP}$ receptor in thrombin-induced platelet signaling.

\section{Methods}

Generation of $G \alpha_{i 2}{ }^{-1-}$ mice. Mice genetically deficient in $G \alpha_{i 2}$ were produced by homologous recombination in embryonic stem cells and blastocyst-mediated transgenesis as described previously (20). Mice used for these experiments were generally sex-matched littermates of heterozygous breeding pairs of a mixed 129/Svter and C57BL/6J genetic background. For some experiments, platelets were pooled from littermates and age- and sexmatched offspring of a large set of heterozygous mating pairs. In these cases mutant and control mice were selected randomly to avoid introducing systematic differences in potential modifier loci derived from the two genetic backgrounds used. All procedures conformed to institutional guidelines and to the Guide for the Care and Use of Laboratory Animals (NIH, Bethesda, Maryland, USA).

Platelet preparation. Following cardiac puncture $0.7 \mathrm{ml}$ of mouse blood was drawn into $0.56 \mathrm{ml}$ of $0.9 \% \mathrm{NaCl}$ and $0.14 \mathrm{ml}$ of TSC (3.8\% trisodium citrate, $\mathrm{pH} 7)$ plus $100 \mathrm{nM}$ prostaglandin $\mathrm{E}_{1}\left(\mathrm{PGE}_{1}\right.$; Sigma Chemical Co., St. Louis, Missouri, USA) for platelet-rich plasma (PRP), or $0.14 \mathrm{ml} \mathrm{ACD} \mathrm{(85} \mathrm{mM} \mathrm{sodium} \mathrm{citrate,} 111$ mM glucose, $71.4 \mathrm{mM}$ citric acid) plus $100 \mathrm{nM} \mathrm{PGE}_{1}$ for washed platelets (WPs) (22). Diluted PRP was obtained after centrifugation of blood from individual mice at $80 \mathrm{~g}$ for 10 minutes in an Eppendorf microcentrifuge. For WPs, after removal of the PRP, the lower phase was diluted with $1 \mathrm{vol}$ of $0.9 \% \mathrm{NaCl} / 10 \% \mathrm{ACD}$ and centrifuged again. This step was repeated, the three PRP samples pooled, centrifuged at $730 \mathrm{~g}$ for $15 \mathrm{~min}$ utes, and the resulting platelet pellet resuspended in CGS $(13 \mathrm{mM}$ sodium citrate, $30 \mathrm{mM}$ glucose, $120 \mathrm{mM}$ $\mathrm{NaCl}$ ) containing $1 \mathrm{U} / \mathrm{ml}$ apyrase (grade VII; Sigma Chemical Co.). After incubation for 15 minutes at $37^{\circ} \mathrm{C}$, platelets were collected by centrifugation and resuspended at $2 \times 10^{8} / \mathrm{ml}$ in HEPES/Tyrode's buffer/BSA (10 mM HEPES, $138 \mathrm{mM} \mathrm{NaCl}, 5.5 \mathrm{mM}$ glucose, $2.9 \mathrm{mM} \mathrm{KCl}, 12 \mathrm{mM} \mathrm{NaHCO} 3, \mathrm{pH} 7.4,0.1 \%$ BSA) at room temperature.

Western blot analysis. Washed mouse platelets were lysed in hypotonic buffer $(10 \mathrm{mM}$ HEPES, $5 \mathrm{mM}$ EDTA, pH 7.4), including a protease inhibitor cocktail (Roche Molecular Biochemicals, Indianapolis, Indiana, USA), by sonication for three times for 3 seconds on ice. After centrifugation at $600 \mathrm{~g}$ for 10 minutes at $4^{\circ} \mathrm{C}$, crude platelet membranes were collected from the supernatant by centrifugation at $20,000 \mathrm{~g}$ for $30 \mathrm{~min}$ utes at $4^{\circ} \mathrm{C}$. Protein samples $(30 \mu \mathrm{g})$ were separated on $10 \%$ SDS-PAGE gels and transferred to PVDF membranes. Membranes were blocked with PBS-T (PBS, $0.05 \%$ Tween 20 ) containing $2.5 \%$ nonfat dry milk, followed by overnight incubation at $4^{\circ} \mathrm{C}$ with anti-G protein $\alpha$ and $\beta$ subunit $A b$ 's $\left(G \alpha_{i 2}\right.$ mouse $m A b$, Chemicon International, Temecula, California, USA; $\mathrm{G \alpha}_{\mathrm{q}}, \mathrm{G \alpha}_{\mathrm{i} 1}$, and $\mathrm{G \alpha}_{\mathrm{i} 3}$ rabbit antisera, Calbiochem-Novabiochem Corp., La Jolla, California, USA; $\mathrm{G}_{z}$ and $\mathrm{G} \beta_{1-4}$ rabbit antisera, Santa Cruz Biotechnology Inc., Santa Cruz, California, USA). After treatment with horseradish peroxidase-conjugated goat anti-mouse or mouse antirabbit Ig (Jackson ImmunoResearch Laboratories Inc., West Grove, Pennsylvania, USA), the blots were developed by enhanced chemiluminescence (ECL; Amersham Pharmacia Biotech, Piscataway, New Jersey, USA).

Determination of cAMP. After pretreatment with 0.5 mM IBMX (3-isobutyl-1-methylxanthine; Research Biochemicals International, Natick, Massachusetts, USA) for 5 minutes at $37^{\circ} \mathrm{C}$, washed mouse platelets $\left(10^{8} / \mathrm{ml}\right.$ in HEPES/Tyrode's buffer/BSA) were incubated in triplicate with antagonists, agonists, and $50 \mu \mathrm{M}$ forskolin (Sigma Chemical Co.) for 5 minutes at $37^{\circ} \mathrm{C}$ (13). Levels of cAMP were determined in ethanol extracts using a radioimmunoassay (Amersham Pharmacia Biotech).

Platelet aggregation and shape change. Aggregation was determined in an aggregometer (Chrono-Log Corp., Havertown, Pennsylvania, USA) with stirring $(1,200$ $\mathrm{rpm})$ at $37^{\circ} \mathrm{C}$ using washed mouse platelets $\left(2 \times 10^{8} / \mathrm{ml}\right.$ in HEPES/Tyrode's buffer/BSA, $1 \mathrm{mM} \mathrm{MgCl} 2,1 \mathrm{mM}$ $\mathrm{CaCl}_{2}$ ) after a recovery period of 1 hour. Human fibrinogen $(0.4 \mathrm{mg} / \mathrm{ml}$, Grade L; American Diagnostics, Inc. Greenwich, Connecticut, USA) was added for ADPdependent aggregation (ADP from Roche Molecular Biochemicals and human $\alpha$-thrombin from Haematologic Technologies, Essex Junction, Vermont, USA). The P2Y $_{12}$ antagonist 2MeSAMP was obtained from Research Biochemicals International. For platelet shape-change measurements $5 \mathrm{mM}$ EDTA was added to washed platelets $\left(5 \times 10^{7} / \mathrm{ml}\right)$ after a 2 -hour recovery period to prevent aggregation, and the decrease in light transmittance upon agonist addition was traced in an aggregometer with an amplified recorder scale setting.

FITC-fibrinogen binding. Diluted mouse PRP was prepared as described above and incubated at $5 \times 10^{7}$ platelets $/ \mathrm{ml}$ with antagonists, agonists, and $60 \mu \mathrm{g} / \mathrm{ml}$ 


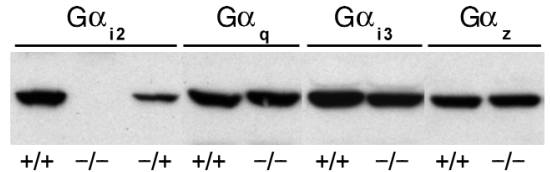

\section{Figure 1}

Expression of $\mathrm{G} \alpha$ subunits in platelet membranes from $\mathrm{G} \alpha_{\mathrm{i} 2^{-}}{ }^{-/}$mice. Western blots of platelet membranes ( $30 \mu \mathrm{g}$ protein) from wild-type $(+/+), G \alpha_{i 2}$ knockout (-/-), and heterozygote (-/+) mice were probed with $G \alpha_{i 2}, G \alpha_{q}, G \alpha_{i 3}$, and $G \alpha_{z} A b$ 's as indicated. Blots shown are representative of at least three independent experiments controlled for load and detectable protein.

FITC-conjugated fibrinogen (human fibrinogen from Enzyme Research Laboratories, South Bend, Indiana, USA, labeled with FITC celite from Molecular Probes Inc., Eugene, Oregon, USA) for 30 minutes at room temperature. To thrombin-containing samples, 2.5 $\mathrm{mM}$ of the peptide GlyProArgPro (Bachem Bioscience Inc., King of Prussia, Pennsylvania, USA) was added to prevent thrombin-mediated fibrin generation. The samples were then transferred to $4^{\circ} \mathrm{C}$ and fixed with $1 \%$ $p$-formaldehyde for 30 minutes. After dilution with 0.5 $\mathrm{ml} 1 \% p$-formaldehyde/PBS the fluorescence of platelet-bound FITC-fibrinogen was analyzed with a FACSort flow cytometer (Becton-Dickinson Immunocytometry Systems, San Jose, California, USA) (22). A FITC-conjugated $\mathrm{Ab}$ raised against mouse integrin $\beta 3$ subunit (anti-mouse CD61; PharMingen, San Diego, California, USA) was used as a positive control.

Intracellular calcium mobilization. Mouse platelets were prepared using the washed platelet procedure until the CGS step described above, except that $\mathrm{PGE}_{1}(100 \mathrm{nM})$ was not added to the blood, but to the pooled diluted PRP. Platelets in CGS were incubated with $1 \mathrm{U} / \mathrm{ml}$ apyrase and $4 \mu \mathrm{M}$ Fura-2AM/0.008\% Pluronic F-127 (Molecular Probes Inc.) for 30 minutes at $37^{\circ} \mathrm{C}$, collected by centrifugation, and resuspended at $2 \times 10^{8} / \mathrm{ml}$ in HEPES/Tyrode's buffer/BSA buffer containing 0.1 $\mathrm{U} / \mathrm{ml}$ apyrase and $1 \mathrm{mM} \mathrm{MgCl}_{2}$. After 1.5-2 hours, peak intracellular calcium ion concentrations in response to ADP and thrombin were determined in a SLM-Aminco AB2 spectrofluorometer (SLM-Aminco, Urbana, Illinois, USA) using the ratio method as described (13).

\section{Results}

Effect of $G \alpha_{i 2}$ gene disruption on platelet expression of $G \alpha$ subtypes. Mice with a disruption of the $\mathrm{G} \alpha_{\mathrm{i} 2}$ gene did not display any obvious abnormalities of the hemostatic system, but the effects on platelet function have not been investigated $(19,20)$. We have found no significant difference in the platelet counts between wildtype and $\mathrm{G \alpha}_{\mathrm{ii}_{2}}{ }^{-/-}$mice $\left(599 \pm 73 \times 10^{3} / \mu \mathrm{l}, n=5\right.$, versus $\left.621 \pm 67 \times 10^{3} / \mu \mathrm{l}, n=5\right)$. The expression of $\mathrm{G \alpha}_{\mathrm{i} 2}$ and other $\mathrm{G} \alpha$ subtypes was analyzed in crude platelet membranes using Western blot analysis. As expected, no $G \alpha_{i 2}$ protein could be detected in membranes from $G \alpha_{i 2}{ }^{-/-}$mice, and the expression of $\mathrm{G} \alpha_{\mathrm{i} 2}$ was reduced in platelet membranes from heterozygous mice (Figure 1). By comparison, no difference was seen in the abundance of $\mathrm{G} \alpha_{\mathrm{q}}$. To determine whether the absence of $\mathrm{G \alpha}_{\mathrm{i} 2}$ resulted in upregulation of other $\mathrm{G}$ proteins capable of inhibiting adenylyl cyclase, as reported for $\mathrm{G \alpha}_{\mathrm{i} 3}$ in SV40-transformed embryonic fibroblasts from $G \alpha_{i 2}{ }^{-/-}$mice (19), the expression levels for $G \alpha_{i 1}, G \alpha_{i 3}$, and $\mathrm{G} \alpha_{z}$ were compared in platelet membranes prepared from wild-type and $G \alpha_{i 2}{ }^{-/-}$mice. No significant difference in the abundance of $\mathrm{G \alpha}_{\mathrm{i} 3}$ and $\mathrm{G} \alpha_{z}$ proteins could be detected (Figure 1). There was also no change in the level of $G \beta$ protein that could reflect different expression of $\beta \gamma$ subunits in $G \alpha_{i 2}{ }^{-/-}$platelets (data not shown). In confirmation of a previous report on human platelets (3), we were unable to detect expression of $\mathrm{G \alpha}_{\mathrm{i1}}$ in wild-type mouse platelet membranes (data not shown). It thus appears that the lack of $G \alpha_{\mathrm{i} 2}$ does not lead to an increased expression in platelets of other $\mathrm{G}$ protein subunits capable of mediating the inhibition of adenylyl cyclase.

Effect of $G \alpha_{i 2}$ gene disruption on the inbibition of adenylyl cyclase in platelets. The $\mathrm{G}$ protein subunit $\mathrm{G}_{\mathrm{i} 2}$ is known to be capable of mediating inhibition of stimulated adenylyl cyclase in many cell types and is also the most abundant $\mathrm{G} \alpha_{i}$ form in platelets. To determine the role of $\mathrm{G \alpha}_{\mathrm{i} 2}$ in the regulation of platelet adenylyl cyclase in intact mouse platelets, we have compared the ability of ADP, thrombin, and epinephrine to inhibit forskolinstimulated cAMP accumulation in washed platelets from wild-type and $G \alpha_{i 2}{ }^{-/-}$mice. ADP inhibited cAMP formation in platelets from wild-type mice resulting in $60 \%$ and $76 \%$ inhibition at 1 and $10 \mu \mathrm{M} \mathrm{ADP}$, respectively (Figure 2a). In platelets from $\mathrm{GO}_{\mathrm{i}^{2}}{ }^{-/-}$mice, however, ADP-dependent repression of cAMP levels was impaired with only $30 \%$ and $52 \%$ inhibition observed at 1 and $10 \mu \mathrm{M}$ ADP, respectively. This suggests that $\mathrm{G \alpha}_{\mathrm{i} 2}$ is important for ADP-dependent inhibition of mouse platelet adenylyl cyclase in vivo. Interestingly, this defect can be detected even in the presence of other inhibitory $G$ proteins, such as $G \alpha_{i 3}$ and $G \alpha_{z}$, which may partially substitute for $\mathrm{G}_{\mathrm{i} 2}$ in $\mathrm{G}_{\mathrm{i}_{2} /-}$ platelets.

Thrombin repressed forskolin-stimulated cAMP accumulation in wild-type mouse platelets, reaching $65 \%$ and $62 \%$ inhibition at 10 and $100 \mathrm{nM}$ thrombin, respectively. This inhibition was impaired in platelets prepared from $\mathrm{GO}_{\mathrm{i} 2}{ }^{-/}$mice with $38 \%$ and $46 \%$ inhibition at 10 and $100 \mathrm{nM}$ thrombin (Figure 2b). To determine whether this defect is based on a direct coupling of $\mathrm{G} \alpha_{\mathrm{i} 2}$ to mouse thrombin receptors or to thrombindependent release of ADP, which then activates the $\mathrm{G \alpha}_{\mathrm{i} 2}$-coupled platelet ADP receptor $\mathrm{P} 2 \mathrm{Y}_{12}$, the cAMP experiment with wild-type platelets was performed in the presence of $2 \mathrm{MeSAMP}$. It has been reported previously that $2 \mathrm{MeSAMP}$ is a selective antagonist of the human platelet $\mathrm{ADP}$ receptor $\left(\mathrm{P} 2 \mathrm{Y}_{12}\right)$, mediating the inhibition of adenylyl cyclase $(13,14)$. We have confirmed the properties of this antagonist on mouse ADP receptors (data not shown). Interestingly, addition of $5 \mu \mathrm{M} 2 \mathrm{MeSAMP}$ prevented the inhibition of cAMP 


\section{Figure 2}

Inhibition of platelet cAMP accumulation by ADP and thrombin in $G \alpha_{i 2}{ }^{-1-}$ mice. (a, b and $\mathbf{d}$ ) In WPs from wild-type mice (filled bars) and $G \alpha_{i 2}$ knockout mice (open bars), cAMP formation was stimulated by forskolin (Control, 100\%) in the presence of increasing concentrations of ADP (a), thrombin (b), and epinephrine (d). (c) Blockade of thrombin-mediated inhibition of cAMP formation by the P2Y 12 ADP receptor antagonist 2MeSAMP. Platelets from wild-type mice treated with forskolin and thrombin (filled bars) were incubated with 2MeSAMP (gray bars). Data shown are the mean \pm SEM of one representative experiment out of at least three performed in triplicate, normalized to cAMP levels in platelets treated with forskolin only (Control, 100\%).
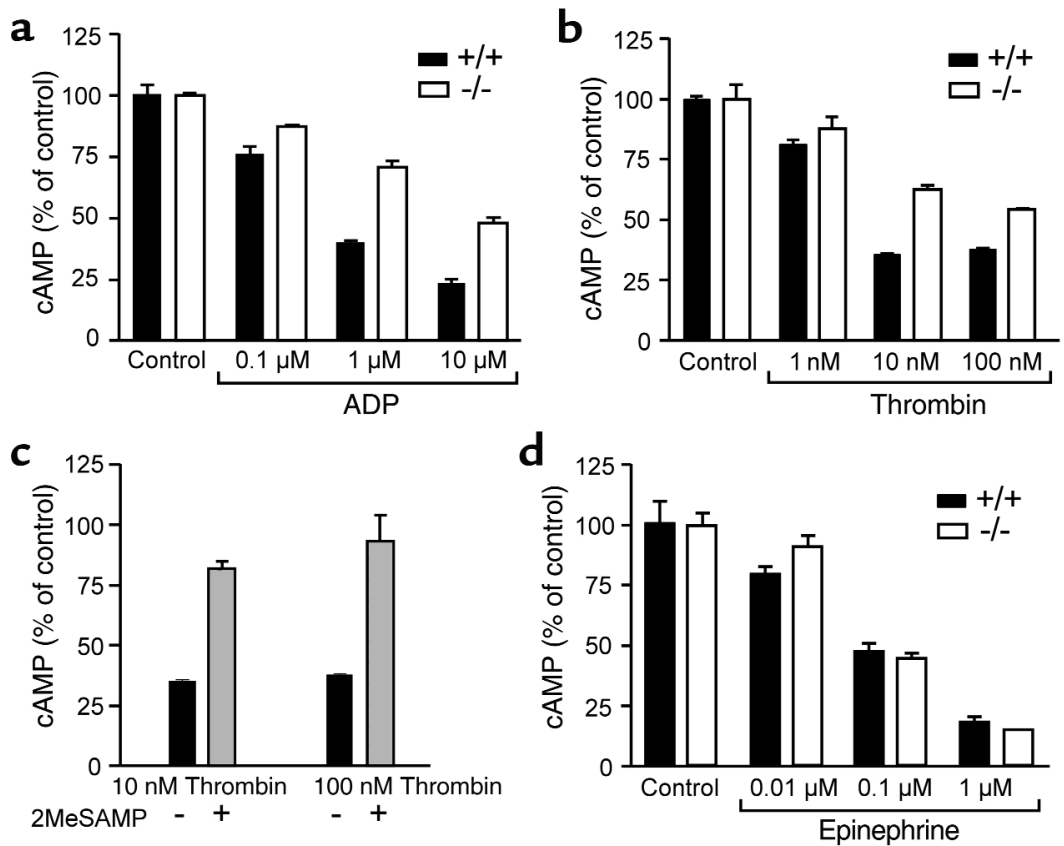

accumulation even at the relatively high thrombin concentration of $100 \mathrm{nM}$ (Figure $2 \mathrm{c}$ ). These results indicate that thrombin-dependent inhibition of platelet adenylyl cyclase is not mediated by thrombin receptors, but by ADP released upon stimulation of platelets activating the $G \alpha_{\mathrm{i} 2}$-coupled ADP receptor $\left(\mathrm{P} 2 \mathrm{Y}_{12}\right)$ in wild-type mice. Therefore, thrombin-dependent inhibition of adenylyl cyclase is defective in $\mathrm{G}_{\mathrm{i} 2}{ }^{-/-}$mice.

By contrast, no significant impairment of epinephrine-mediated inhibition of adenylyl cyclase could be detected (Figure 2d). Epinephrine inhibited forskolinstimulated cAMP formation in wild-type platelets by $21 \%, 53 \%$, and $80 \%$ and in $\mathrm{G}_{i 2}{ }^{-/-}$platelets by $9 \%, 55 \%$, and $86 \%$ at $0.01,0.1$, and $1 \mu \mathrm{M}$ epinephrine, respectively. This inhibition suggests either that $G \alpha_{i 2}$ does not mediate epinephrine-dependent inhibition of platelet adenylyl cyclase or that other inhibitory $G$ proteins, e.g., $\mathrm{G} \alpha_{\mathrm{i} 3}$ or $\mathrm{G} \alpha_{z}$, can functionally replace $\mathrm{G} \alpha_{\mathrm{i} 2}$ in $G \alpha_{i 2}{ }^{-/}$ platelets. The former interpretation is consistent with the suggestion based on studies with $\mathrm{Go}_{\mathrm{z}}{ }^{-/-}$platelets that the effects of epinephrine appear to be predominantly mediated by $\mathrm{G} \alpha_{z}(7)$.

Effect of $G \alpha_{i 2}$ gene disruption on platelet aggregation and integrin activation. To determine the role of $\mathrm{G \alpha}_{\mathrm{i} 2}$ in platelet aggregation, we compared ADP- and thrombin-induced aggregation of washed platelets from wildtype and $G \alpha_{i 2}{ }^{-/-}$mice. ADP induced half-maximal aggregation of wild-type platelets at about $0.3 \mu \mathrm{M}$ and full aggregation at $10 \mu \mathrm{M}$ (Figure 3a). In $G \alpha_{i 2}^{-1-}$ platelets, the final extent of aggregation was reduced by $35-67 \%$ and the slopes of aggregation tracings were diminished as well. Even at the very high ADP concentration of $100 \mu \mathrm{M}$, aggregation was still impaired by 21-38\% (data not shown). These results support the conclusion that $\mathrm{G} \alpha_{\mathrm{i} 2}$ is not only important for the inhibition of platelet adenylyl cyclase but also for platelet aggregation. ADP-dependent aggregation was also investigated in platelets from heterozygous mice. No defect was detected, which is consistent with the assumption that the amount of $\mathrm{G} \alpha_{\mathrm{i} 2}$ in platelets from heterozygous mice is sufficient to saturate the small number of ADP receptors (data not shown).

Thrombin-induced aggregation was also impaired in platelets from $G \alpha_{i 2}^{-/-}$mice, but only at threshold concentrations of thrombin that induce slightly reversible aggregation (Figure 3b). With platelets from $\mathrm{Go}_{i 2}{ }^{-1-}$ mice, maximum aggregation was reduced to about $50 \%$ when compared with wild-type platelets, and aggregation was almost completely reversible within 5 minutes. At a fivefold higher concentration of thrombin, which induces irreversible aggregation in wild-type platelets, no effect of $\mathrm{G}_{\mathrm{i} 2}$ gene disruption was observed. Since aggregation induced by low concentrations of thrombin has been shown previously to be dependent on released ADP (21), the $\mathrm{P}_{2} \mathrm{Y}_{12} \mathrm{ADP}$ receptor antagonist 2MeSAMP was included in the experiment. Blockade of the $\mathrm{P} 2 \mathrm{Y}_{12}$ receptor on wild-type platelets by $10 \mu \mathrm{M} 2 \mathrm{MeSAMP}$ mimicked essentially the observations with thrombininduced platelet aggregation of platelets from $G \alpha_{i 2}{ }^{-/}$ mice (Figure 3c). Apparently, $G \alpha_{\mathrm{i} 2}$ does not couple to mouse platelet thrombin receptors in the pathway leading to aggregation, or $G \alpha_{i 3}$ together with $G_{q}$, and possibly other $G$ proteins can functionally replace $G \alpha_{i 2}$.

Platelet aggregation requires activation of the platelet integrin $\alpha_{\text {II }} \beta_{3}$ (GPIIb-IIIa) enabling the binding of soluble fibrinogen with high affinity and avidity. Integrin activation was determined as an ADP or thrombininduced increase in binding of FITC-conjugated fibrinogen to platelets using flow cytometry. FITC-fibrinogen binding to wild-type platelets was induced 4.1-fold, 13-fold, and 18-fold by 1, 10, and $100 \mu \mathrm{M}$ ADP, respectively (Figure 4a). By comparison, in $G \alpha_{i 2}^{-/-}$ 
a
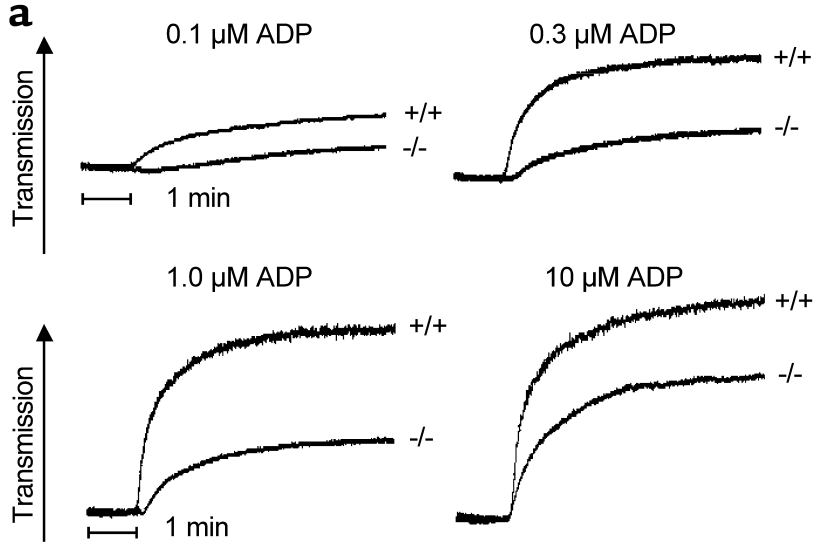

b
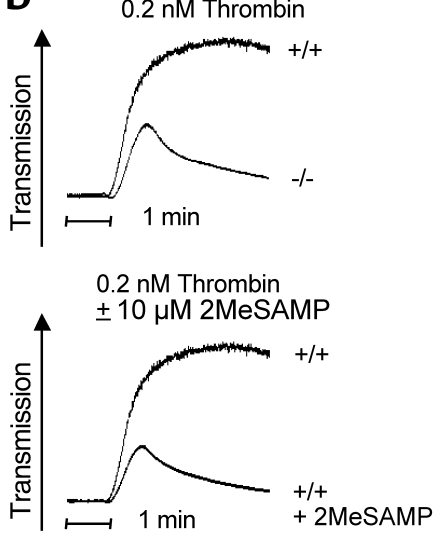
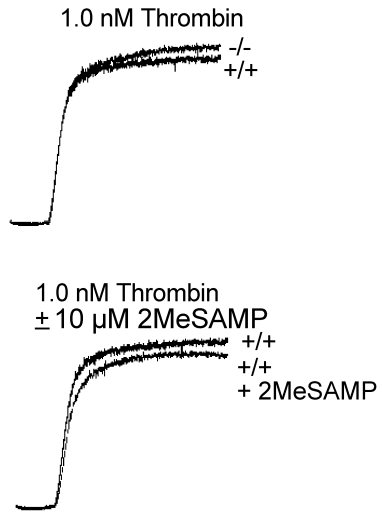

Figure 3

Platelet aggregation in $\mathrm{Go}_{\mathrm{i} 2}{ }^{-/-}$mice. (a) ADP-induced aggregation ofWPs of wild-type mice $(+/+)$and $\mathrm{Go}_{\mathrm{i} 2}$ knockout mice (-/-) was determined as an increase in light transmission in an aggregometer. (b) Aggregation responses to threshold $(0.2 \mathrm{nM})$ and higher $(1 \mathrm{nM})$ concentrations of thrombin were obtained with wild-type (+/+) and $\mathrm{G} \alpha_{\mathrm{i} 2}$ knockout platelets (-/-), and with wild-type (+/+) platelets in the presence and absence of the P2Y ${ }_{12}$ ADP receptor antagonist 2MeSAMP. The aggregometer tracings shown are representative of at least three independent experiments.

platelets, induction of FITC-fibrinogen binding was strongly reduced even at high ADP concentrations, resulting in an induction factor of only 1.4, 1.8, and 2.5. Apparently, $G \alpha_{\mathrm{i} 2}$ is required for ADP-mediated insideout integrin signaling with little substitution by other G proteins still present in $G \alpha_{i 2}{ }^{-/-}$platelets. Thrombininduced FITC-fibrinogen binding is also reduced in $G \alpha_{i 2}{ }^{-/}$platelets, however, to a lesser degree (Figure 4b). FITC-fibrinogen binding was induced 15 - and 23 -fold by 10 and $100 \mathrm{nM}$ thrombin in wild-type platelets and 7- and 20-fold in $\mathrm{GO}_{i 2}{ }^{-/}$platelets, respectively. In wildtype mouse platelets, blockade of the $\mathrm{P}_{2} \mathrm{Y}_{12} \mathrm{ADP}$ receptor linked to inhibition of adenylyl cyclase with $100 \mu \mathrm{M}$ $2 \mathrm{MeSAMP}$ also resulted in a reduction of thrombinmediated FITC-fibrinogen binding (Figure 4c). These data support the hypothesis that $\mathrm{G \alpha}_{\mathrm{i} 2}$ is involved in inside-out integrin signaling by thrombin predominantly through released ADP.
Effect of $G \alpha_{i 2}$ gene disruption on platelet shape change and calcium mobilization. ADP mediates platelet shape change through the $\mathrm{P}_{2} \mathrm{Y}_{1}$ receptor, which is linked to intracellular calcium mobilization. Antagonists of the $\mathrm{P}_{2} \mathrm{Y}_{12} \mathrm{ADP}$ receptor coupled to inhibition of adenylyl cyclase do not block shape change $(8,13,21)$. Furthermore, no ADPdependent shape change has been detected in platelets from mice in which the $G \alpha_{q}$ gene has been disrupted (6, 23). However, signaling pathways independent of $G \alpha_{q}$ and calcium have been proposed to be involved in ADPmediated shape change $(5,24)$. As shown in Figure 5, platelet shape change upon addition of ADP was not affected in $\mathrm{GO}_{\mathrm{i} 2}{ }^{-1-}$ mice. This is consistent with $\mathrm{G} \alpha_{\mathrm{q}}$ being at least the predominant mediator of this response, although some involvement of $\mathrm{G \alpha}_{\mathrm{i} 2}$, substituted by $\mathrm{G \alpha}_{\mathrm{i} 3}$ and $\mathrm{G} \alpha_{z}$ in $G \alpha_{i 2}{ }^{-/-}$platelets, cannot be excluded.

The $\mathrm{G} \alpha_{\mathrm{q}}$ pathway and intracellular calcium mobilization do not appear to be required for thrombin- $\mathbf{a}$

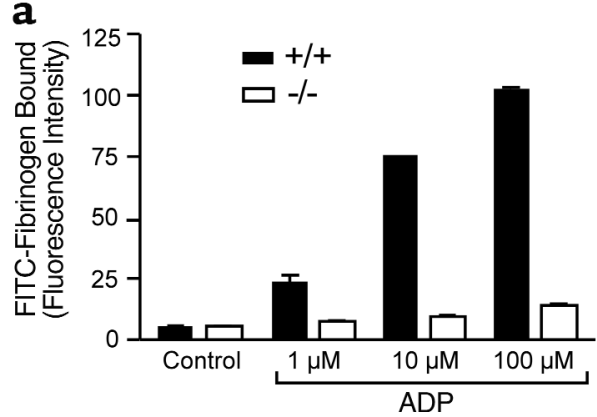

b

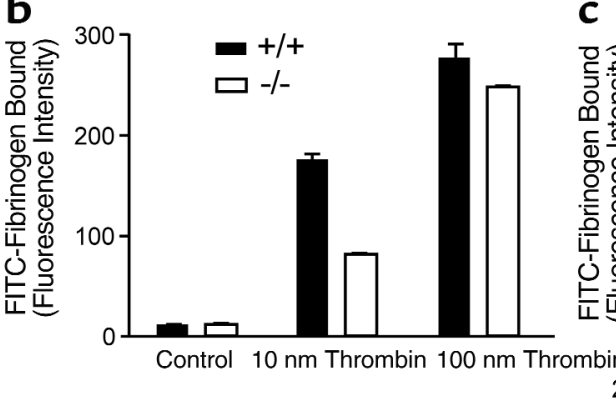

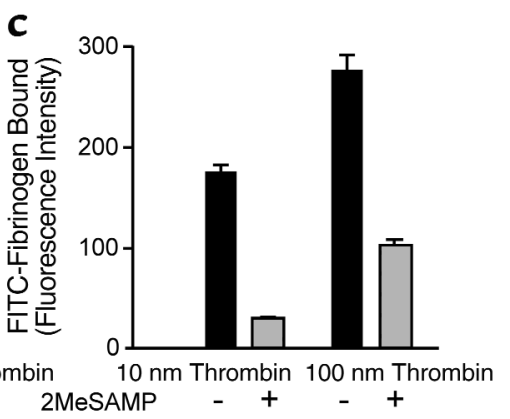

Figure 4

Stimulation of FITC-fibrinogen binding to platelets from $\mathrm{G}_{\mathrm{i} 2}{ }^{-/-}$mice. (a and b) Diluted PRP from wild-type (filled bars) and G $\alpha_{\mathrm{i} 2} \mathrm{knockout}$ mice (open bars) was incubated with FITC-fibrinogen in the absence (Control) and presence of increasing concentrations of ADP and thrombin. The mean fluorescence intensity of platelet-bound FITC-fibrinogen was determined by flow cytometry. (c) Blockade of thrombin-mediated stimulation of FITC-fibrinogen binding by the P2Y ${ }_{12}$ ADP receptor antagonist 2MeSAMP. Platelets from wild-type mice treated with thrombin were incubated in the absence (filled bars) and presence of the P2Y 12 ADP receptor antagonist 2MeSAMP (gray bars). Data shown are the mean \pm SEM of one representative experiment out of at least three performed in duplicate. 


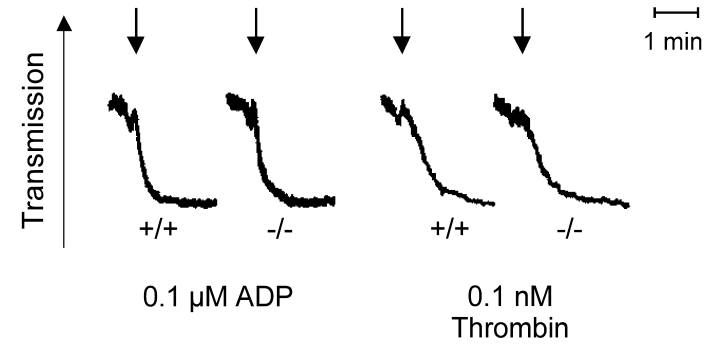

Figure 5

Platelet shape change in $\mathrm{G}_{\mathrm{i}_{2}}{ }^{-/-}$mice. Shape change in response to ADP and thrombin was determined in WPs from wild-type (+/+) and $G \alpha_{i 2}$ knockout mice (-/-) as a decrease of light transmission in an aggregometer. Arrows indicate addition of agonists. Aggregation was prevented by addition of EDTA, and the amplitude of the tracings was amplified for clarity. The aggregometer tracings shown are representative of at least three independent experiments.

dependent platelet shape change, but $\mathrm{G \alpha}_{12}$ and/or $\mathrm{G}_{13}$ might be involved $(5,6)$. The contribution of $\mathrm{G}_{\mathrm{i}}$ proteins has not been investigated. Here we show that the shape change response in platelets from $G \alpha_{i 2}{ }^{-1-}$ mice was not impaired, even at low concentrations of thrombin ( $0.1 \mathrm{nM}$; Figure 5$)$, suggesting that $\mathrm{G \alpha}_{\mathrm{i} 2}$ is not a major component in the signaling pathway for thrombin-dependent platelet shape change.

Intracellular calcium mobilization is a critical event for platelet activation and has been attributed to the $\mathrm{G}_{\mathrm{q}}$ pathway. Consequently, in platelets from $\mathrm{G \alpha}_{\mathrm{q}}{ }^{-/-}$mice no intracellular calcium mobilization was detected in response to $\mathrm{ADP}$, thrombin, or other platelet agonists (6). However, the contribution of other $G$ proteins, e.g., $\beta \gamma$ subunits released from $G \alpha_{\mathrm{i} 2}$ and capable of activation of phospholipase $C \beta$, cannot be excluded from those data. Wild-type and $\mathrm{GO}_{\mathrm{i} 2}{ }^{-1-}$ platelets were analyzed for intracellular calcium mobilization using the fura- 2 ratio method. In three independent experiments no impairment of responses to 1 and $10 \mu \mathrm{M}$ ADP or $1 \mathrm{nM}$ thrombin was found in $\mathrm{Go}_{i 2}{ }^{-/-}$platelets (data not shown). These findings are consistent with the hypothesis that $\mathrm{G}_{\mathrm{i} 2}$ does not play any role in this signaling pathway.

\section{Discussion}

This study provides direct evidence for the importance of $\mathrm{G \alpha}_{\mathrm{i} 2}$ for platelet activation resulting in aggregation. Platelets from $G \alpha_{i 2}{ }^{-/-}$mice have been found to be defective for ADP-dependent inhibition of adenylyl cyclase, integrin activation, and aggregation. Intracellular calcium mobilization and shape change were not affected, which is consistent with previous results with $G \alpha_{q}^{-1}$ platelets and selective ADP receptor antagonists, which suggested a predominant role of the $\mathrm{G}_{\mathrm{q}}$ pathway for these responses $(6,23)$. Lack of expression of $G \alpha_{i 2}$ resulted in only partial signaling defects. It is conceivable that other inhibitory $G$ proteins expressed in the $G \alpha_{i 2}{ }^{--}$platelets, such as $G \alpha_{i 3}$ and maybe $G \alpha_{z}$, can be activated by ADP receptors even though they might not couple efficiently to these receptors in wild-type platelets when $\mathrm{G} \alpha_{\mathrm{i} 2}$ is present. This would be consistent with the finding that $G \alpha_{z}^{-/-}$platelets display normal cAMP signaling in response to ADP and thrombinreceptor stimulation (7). The fact that any defects could be detected in the presence of a likely excess of other inhibitory $G$ proteins supports the crucial role of $\mathrm{G \alpha}_{\mathrm{i} 2}$ in this signaling pathway.

The finding that integrin activation was more affected in the $\mathrm{Go}_{\mathrm{i2}}{ }^{-/-}$platelets than inhibition of adenylyl cyclase points to a pathway between $\mathrm{G \alpha}_{\mathrm{i} 2}$ and the integrin that is independent of cAMP and strongly suggests a pivotal role for $\mathrm{G} \alpha_{\mathrm{i} 2}$ in inside-out signaling. However, the almost complete loss of ADP-dependent integrin activation did not result in a similar dramatic effect on platelet aggregation, although integrin activation is thought to be a prerequisite of aggregation. There are at least two possible explanations for this apparent discrepancy. First, platelets from $\beta_{3}$ integrin heterozygous $-/+$ mice that express only $50 \%$ of wild-type level of GPIIb-IIIa are still capable of full aggregation (25). Second, in contrast to measurements of FITC-fibrinogen binding, aggregation assays are performed with an excess of fibrinogen and stirring, facilitating integrin outside-in signaling that enhances aggregation (1). A contribution of released thromboxane $\mathrm{A}_{2}$ to the observed aggregation can be excluded, because addition of a thromboxane $\mathrm{A}_{2}$ receptor antagonist did not affect aggregation induced by ADP or thrombin (H.-M. Jantzen, unpublished observations).

The data in the present study support a role of $\mathrm{G \alpha}_{\mathrm{i} 2}$ in thrombin-dependent inhibition of adenylyl cyclase, integrin activation, and aggregation, although the effect was less pronounced than with ADP. Interestingly, blockade of the ADP receptor mediating inhibition of adenylyl cyclase $\left(\mathrm{P}_{2} \mathrm{Y}_{12}\right)$ by $2 \mathrm{MeSAMP}$ in wild-type platelets had effects on thrombin signaling that were similar to those of the $\mathrm{G} \alpha_{\mathrm{i} 2}$ knockout. This supports the hypothesis that $\mathrm{G} \alpha_{\mathrm{i} 2}$ does not directly couple to mouse platelet thrombin receptors, but instead ADP released upon thrombin activation of platelets activates $\mathrm{G \alpha}_{\mathrm{i} 2}$ coupled ADP receptors. These results are also consistent with other reports emphasizing the role of released ADP and a $\mathrm{G}_{\mathrm{i}}$-linked ADP receptor in platelet activation by other agonists $(21,26-29)$. The observation that the $\mathrm{P} \mathrm{Y}_{12}$ antagonist $2 \mathrm{MeSAMP}$ interfered with thrombin effects on adenylyl cyclase and fibrinogen binding to a larger extent than did the $G \alpha_{i 2}$ gene disruption, substantiates the conclusion above that the $\mathrm{P}_{2} \mathrm{Y}_{12}$ receptor couples to other proteins of the $G_{i}$ family in addition to $\mathrm{G \alpha}_{\mathrm{i} 2}$. The findings presented here suggesting that mouse thrombin receptors do not directly mediate inhibition of adenylyl cyclase in intact platelets support the observation that the cloned thrombin receptors PAR3 and PAR4 do not couple to adenylate cyclase (30). Unlike mouse platelets, human platelets express PAR1 instead of PAR3, and PAR1 is capable of mediating inhibition of adenylyl cyclase, indicating a different role for $\mathrm{Ga}_{\mathrm{i} 2}$ in thrombin signaling in human platelets (31).

The signaling cascade between $\mathrm{G}_{\mathrm{i} 2}$ and activation of the platelet integrin $\alpha_{\text {IIb }} \beta_{3}$ (GPIIb-IIIa) still remains to be elu- 
cidated. $G \alpha_{\mathrm{i} 2}$ mediates inhibition of adenylyl cyclase, but direct inhibition of the enzyme, even with concomitant activation of the $G_{q}$ pathway, is not sufficient for platelet aggregation (16-18). Since high cAMP levels prevent platelet activation, the phosphorylation-dephosphorylation equilibrium of substrates of the cAMP-dependent protein kinase A might be important for inside-out signaling. Alternatively, cAMP and $\mathrm{G} \alpha_{\mathrm{i} 2}$ could directly interact with Epac and Rap1GAPII, respectively, which are regulators of Rap1, a small guanine nucleotide-binding protein activated by ADP and thrombin (32-34).

This study demonstrates a critical role for $\mathrm{G \alpha}_{\mathrm{i} 2}$ in platelet activation, especially by ADP. However, it is possible that the absence of the $\beta \gamma$ subunits normally released from activated $\mathrm{G} \alpha_{\mathrm{i} 2}$ and not the lack of $\mathrm{G} \alpha_{\mathrm{i} 2}$ per se, is responsible for some of the observed defects. For example, $\beta \gamma$ subunits can activate isoforms of phosphoinositide-3-OH kinase (PI 3-kinase). PI 3-kinases and released ADP acting on the adenylyl cyclase-coupled $\mathrm{ADP}$ receptor $\left(\mathrm{P}_{2} \mathrm{Y}_{12}\right)$ appear to be important for the stabilization of platelet aggregates $(1,21,27,29)$. Alternatively, released $\beta \gamma$ subunits may activate nonreceptor tyrosine kinases and other signaling proteins $(1,35)$. The challenge for future research will be the identification of the missing links of the signaling cascade between $\mathrm{G \alpha}_{\mathrm{i} 2}$ and platelet integrin $\alpha_{\mathrm{II}} \beta_{3}$ (GPIIb-IIIa). The analysis of platelet function from mice lacking $\mathrm{Go}_{\mathrm{i} 2}$, other signaling proteins, or the $\mathrm{G \alpha}_{\mathrm{i} 2}$-coupled $\mathrm{ADP}$ receptor $\mathrm{P} 2 \mathrm{Y}_{12}$ in combination with selective inhibitors will facilitate progress toward this goal.

\section{Acknowledgments}

We thank F. Deguzman and the COR Therapeutics Inc. animal facility, G. Li and E. Thompson for technical assistance. We thank E. Reynolds and C. Homcy for help with initiating the project; D. Oksenberg, D. Law, D. Phillips, C. Homcy, V. Ramakrishnan, and R. Scarborough for advice or critical reading of the manuscript; and R. Wong, D. DeGuzman and D. Stockett for help with the figures. D.S. Milstone was supported by grants from the NIH (HL-5409 and HL-30628). R.M. Mortensen was supported by NIH grant R01 HL-58606.

1. Shattil, S.J., Kashiwagi, H., and Pampori, N. 1998. Integrin signaling: the platelet paradigm. Blood. 91:2645-2657.

2. Williams, A.G., et al. 1990. Identification of the pertussis toxin-sensitive $\mathrm{G}$ proteins in platelets, megakaryocytes, and human erythroleukemia cells. Blood. 76:721-730.

3. Ohlmann, P., et al. 1995. The human platelet ADP receptor activates $\mathrm{G}_{\mathrm{i} 2}$ proteins. Biochem. J. 312:775-779.

4. Brass, L.F., Manning, D.R., Cichowski, K., and Abrams, C.S. 1997. Signaling through $G$ proteins in platelets: to the integrins and beyond. Thromb. Haemost. 78:581-589.

5. Offermanns, S. 2000. The role of heterotrimeric $G$ proteins in platelet activation. Biol. Chem. 381:389-396.

6. Offermanns, S., Toombs, C.F., Hu, Y.H., and Simon, M.I. 1997. Defective platelet activation in $\mathrm{G} \alpha_{\mathrm{q}}$-deficient mice. Nature. 389:183-186.

7. Yang, J., et al. 2000. Loss of signaling through the $G$ protein, $G_{z}$, results in abnormal platelet activation and altered responses to psychoactive drugs. Proc. Natl. Acad. Sci. USA. 97:9984-9989.

8. Jin, J., Daniel, J.L., and Kunapuli, S.P. 1998. Molecular basis for ADPinduced platelet activation. II. The P2Y1 receptor mediates ADP-induced intracellular calcium mobilization and shape change in platelets. J. Biol. Chem. 273:2030-2034.

9. Savi, P., et al. 1998. Role of P2Y1 purinoceptor in ADP-induced platelet activation. FEBS Lett. 422:291-295.

10. Hechler, B., Eckly, A., Ohlmann, P., Cazenave, J.P., and Gachet, C. 1998. The $\mathrm{P}_{2} \mathrm{Y}_{1}$ receptor, necessary but not sufficient to support full ADPinduced platelet aggregation, is not the target of the drug clopidogrel. Br. J. Haematol. 103:858-866.

11. Fagura, M.S., et al. 1998. $\mathrm{P}_{2} \mathrm{Y}_{1}$-receptors in human platelets which are pharmacologically distinct from $\mathrm{P}_{2} \mathrm{Y}_{\mathrm{ADP}}$-receptors. Br. J. Pharmacol. 124: $157-164$.

12. Geiger, J., Honig-Liedl, P., Schanzenbacher, P., and Walter, U. 1998. Ligand specificity and ticlopidine effects distinguish three human platelet ADP receptors. Eur. J. Pharmacol. 351:235-246.

13. Jantzen, H.M., et al. 1999. Evidence for two distinct G-protein-coupled ADP receptors mediating platelet activation. Thromb. Haemost. 81:111-117.

14. Hollopeter, G., et al. 2001. Identification of the platelet ADP receptor targeted by antithrombotic drugs. Nature. 409:202-207.

15. Jin, J., and Kunapuli, S.P. 1998. Coactivation of two different G proteincoupled receptors is essential for ADP-induced platelet aggregation. Proc. Natl. Acad. Sci. USA. 95:8070-8074.

16. Haslam, R.J., Davidson, M.M., and Desjardins, J.V. 1978. Inhibition of adenylate cyclase by adenosine analogues in preparations of broken and intact human platelets. Evidence for the unidirectional control of platelet function by cyclic AMP. Biochem. J. 176:83-95.

17. Savi, P., Pflieger, A.M., and Herbert, J.M. 1996. cAMP is not an important messenger for ADP-induced platelet aggregation. Blood Coagul. Fibrinolysis. 7:249-252.

18. Daniel, J.L., Dangelmaier, C., Jin, J., Kim, Y.B., and Kunapuli, S.P. 1999. Role of intracellular signaling events in ADP-induced platelet aggregation. Thromb. Haemost. 82:1322-1326.

19. Rudolph, U., Spicher, K., and Birnbaumer, L. 1996. Adenylyl cyclase inhibition and altered $G$ protein subunit expression and ADP-ribosylation patterns in tissues and cells from $\mathrm{G}_{\mathrm{i} 2} \alpha-/-$ mice. Proc. Natl. Acad. Sci. USA. 93:3209-3214.

20. Nagata, K., Ye, C., Jain, M., Milstone, D.S., Liao, R., and Mortensen, R.M. 2000. $G \alpha_{i 2}$ but not $G \alpha_{i 3}$ is required for muscarinic inhibition of contractility and calcium currents in adult cardiomyocytes. Circ. Res. 87:903-909.

21. Cattaneo, M., and Gachet, C. 1999. ADP receptors and clinical bleeding disorders. Arterioscler. Thromb. Vasc. Biol. 19:2281-2285.

22. Law, D.A., et al. 1999. Integrin cytoplasmic tyrosine motif is required for outside-in $\alpha \operatorname{IIb} \beta 3$ signalling and platelet function. Nature. 401:808-811.

23. Ohlmann, P., et al. 2000. ADP induces partial platelet aggregation without shape change and potentiates collagen-induced aggregation in the absence of Goq. Blood. 96:2134-2139.

24. Paul, B.Z., Daniel, J.L., and Kunapuli, S.P. 1999. Platelet shape change is mediated by both calcium-dependent and -independent signaling pathways. Role of p160 Rho-associated coiled-coil-containing protein kinase in platelet shape change. J. Biol. Chem. 274:28293-28300.

25 . Hodivala-Dilke, K.M., et al. 1999. $\beta_{3}$-integrin-deficient mice are a model for Glanzmann thrombasthenia showing placental defects and reduced survival. J. Clin. Invest. 103:229-238.

26. Paul, B.Z., Jin, J., and Kunapuli, S.P. 1999. Molecular mechanism of thromboxane $\mathrm{A}_{2}$-induced platelet aggregation. Essential role for $\mathrm{P}_{2} \mathrm{~T}_{A C}$ and $\alpha_{2 \mathrm{~A}}$ receptors. J. Biol. Chem. 274:29108-29114.

27. Trumel, C., et al. 1999. A key role of adenosine diphosphate in the irreversible platelet aggregation induced by the PAR1-activating peptide through the late activation of phosphoinositide 3-kinase. Blood. 94:4156-4165.

28. Jung, S.M., and Moroi, M. 2000. Signal-transducing mechanisms involved in activation of the platelet collagen receptor integrin $\alpha_{2} \beta_{1}$.J. Biol. Chem. 275:8016-8026.

29. Storey, R.F., et al. 2000 . The central role of the $\mathrm{P}_{2 T}$ receptor in amplification of human platelet activation, aggregation, secretion and procoagulant activity. Br. J. Haematol. 110:925-934.

30. Faruqi, T.R., Weiss, E.J., Shapiro, M.J., Huang, W., and Coughlin, S.R. 2000. Structure-function analysis of protease-activated receptor 4 tethered ligand peptides. Determinants of specificity and utility in assays of receptor function. J. Biol. Chem. 275:19728-19734.

31. Coughlin, S.R. 2000. Thrombin signaling and protease-activated receptors. Nature. 407:258-264.

32. Franke, B., Akkerman, J.W., and Bos, J.L. 1997. Rapid Ca ${ }^{2+}$-mediated activation of Rap1 in human platelets. EMBO J. 16:252-259.

33. de Rooij, J., et al. 1998. Epac is a Rap1 guanine-nucleotide-exchange factor directly activated by cyclic AMP. Nature. 396:474-477.

34. Mochizuki, N., et al. 1999. Activation of the ERK/MAPK pathway by an isoform of rap1GAP associated with $\mathrm{G \alpha}_{\mathrm{i}}$. Nature. 400:891-894.

35. Clapham, D.E., and Neer, E.J. 1997. G protein beta gamma subunits. Annu. Rev. Pharmacol. Toxicol. 37:167-203. 